\title{
A comparative analysis of the effect of low-cost fish and commercially compounded feed on growth performance and organoleptic quality of hybrid grouper (Epinephelus fuscoguttatus $\times$ Epinephelus lanceolatus) in cage farming in Kuala Penyu, Sabah, and nutritional costs
}

\author{
Wei Kang Chor ${ }^{1 *}$, Victor Charlie Andin ${ }^{1}$, Chitra Devi Gopalakrishnan ${ }^{1}$, Amierah Amer ${ }^{1}$, \\ Shaheera Mohamed', Hiroyoshi Matsumoto² and Leong Seng Lim ${ }^{3}$ \\ ${ }^{1}$ WWF-Malaysia, 1 Jalan PJS 5/28A, Petaling Jaya Commercial Centre (PJCC), 46150 Petaling Jaya, Selangor, \\ Malaysia \\ ${ }^{2}$ Borneo Marine Farm Sdn. Bhd., B1201, 12 th Floor, Wisma Merdeka Phase 2, Jalan Tun Razak, 88000, Kota \\ Kinabalu, Sabah, Malaysia \\ ${ }^{3}$ Borneo Marine Research Institute, Universiti Malaysia Sabah, Jalan UMS, 88400 Kota Kinabalu, Sabah, Malaysia
}

${ }^{*}$ Corresponding author: cweikang@wwf.org.my

\begin{abstract}
A 25-week feeding trial was conducted to assess the growth performance, organoleptic quality, and to estimate the viability of nourishing hybrid grouper (Epinephelus fuscoguttatus $x$ Epinephelus lanceolatus) with low-cost fish (LCF) and commercially compound feed (CCF). A group of 3600 juvenile fish (182g) were released in four sea cages and fed with either LCF or CCF in duplicate. At the end of the trial, the hybrid grouper provided LCF attained a significantly higher $(\mathrm{P}<0.05)$ final body weight $(971.00 \pm 24.04 \mathrm{~g})$ than those fed with CCF $(838.50 \pm 17.68 \mathrm{~g})$. While the estimated feed cost of hybrid grouper fed with LCF (RM7.84 \pm 0.45 ) was lower than those fed with CCF (RM9.28 \pm 0.37 ), no significant difference was found in the fish survival and there was no clear bias in consumer preferences for either fish fed with LCF or CCF (P>0.05). Although technicalities of fish fed with LCF suggest that LCF is more efficient than CCF, feeding LCF to high-value fish is an unsustainable practice as LCF is usually obtained through trawling - a destructive fishing method for the marine ecosystem. Therefore, feeding with CCF without the use of LCF as the source of protein for its fishmeal will contribute to sustainable aquaculture. In order to convince the local farmers in Sabah to adopt the practice of feeding CCF, future research should focus on completing the species-specific diet formulation to promote optimum growth, and find ways to reduce the CCF local selling price.
\end{abstract}

Keywords: Hybrid grouper, Forage fish, Commercial feed, Growth performance, Organoleptic quality, Feed cost

\section{Introduction}

In the mariculture industry, growing species of high trophic levels often relies heavily on the low-cost fish (LCF, also commonly referred to as trash fish or prey fish) for feeding. LCF is defined as the fish that fetch a low price in the market by virtue of their small size or low consumer preferences. These fish are usually landed as by-catch, mainly from the unsustainable fishing methods such as bottom trawling which are associated with negative impacts to the environment such as population depletion and sea-floor degradation. Use of LCF for feeding raises the concern about other issues, including water pollution caused by excessive nutrient load in from uneaten LCF and the vast potential of disease transmission to the cultured fish (Sim et al., 2005; Gomez et al., 2010; Kim, 2015; Lajimin et al., 2015). Therefore, the commercially compounded feed (CCF) is recommended as a sustainable alternative to LCF, based on its storage convenience and better results in promoting fish growth, feed efficiencies and cost- saving, especially for the grouper farming (Rachmansyah et al., 2009; Shapawi et al., 2011; Ng, 2017; Ching et al., 2019).
The hybrid grouper (Epinephelus fuscoguttatus $\times E$. lanceolatus) is a popular fish for the mariculture industry, especially in the Southeast Asia region (Shapawi et al., 2018). This fish was first produced at Universiti Malaysia Sabah (UMS) in 2006, through the hybridisation between tiger grouper (E. fuscoguttatus) and giant grouper (E. lanceolatus) (Ch'ng and Senoo, 2008). It has since emerged as one of the most commonly farmed and traded marine finfish in Southeast Asia. The hybrid shows combined attributes of both of its parents: fast-growth, resilience and good taste (Shapawi et al., 2018).

Sabah is a strategic region for sea cage farming due to extended coastline. The hybrid grouper is the most widely cultured grouper in this region (DoFM, 2018). Although the advantages of feeding CCF over LCF have been reported in previous studies, the acceptance to use CCF is low among the marine finfish farmers in Sabah, especially those operating on a small scale. Through the interview sessions with the local farmers in Penang, Selangor, Johor and Sabah, it emerged that for the majority of the farmers the production cost of using CCF is higher compared to LCF, and the hybrid 
groupers fed with LCF grew faster than those fed with CCF. In addition, some farmers believed that the farmed fish using LCF tasted better than the CCF-fed fish. Nevertheless, these claims and perceptions have never been investigated up-todate. Therefore, this study was aimed to assess and compare the estimated feed cost, growth performance and the organoleptic quality of the cage-cultured hybrid grouper fed LCF and CCF, in the hope that the outcome could contribute to a better understanding of the appropriate feeding management for grouper aquaculture in Sabah.

\section{Methodology}

\section{Fish farming and sampling}

A feeding trial was conducted over a period of 25 weeks in Kuala Penyu district of Sabah by Borneo Marine Farm Sdn. Bhd. Juvenile fish obtained from a local nursery were acclimated to farm conditions and grown to the required size prior to the feeding trial. As many as 3600 specimens of the hybrid grouper of an initial body weight of approximately 182 g each were released into four cages of the size 10'x 20 '. The stocking density was $900 \mathrm{fish} /$ cage). Fish in two cages were fed with the CCF, while the other two were fed with LCF. The fish were fed until apparent satiation for six days consecutively. The feed intake and mortality of the fish were recorded daily, and 100 fish from each cage were bulkweighed after every five weeks. At the end of this feeding trial, the bulk weight of batches of 10 fish from each cage was measured to obtain the average final body weight. Additionally, two fish from each cage were sampled for a whole body proximate composition analysis, and another three were sampled for the organoleptic test.

\section{Growth performance and feed-cost estimation}

Weight gain (WG), specific growth rate (SGR), survival ratio (SR), daily feed intake (DFI), feed conversion ratio (FCR), and protein efficiency ratio (PER) of the hybrid grouper fed with CCF or LCF were calculated using the following formula:

WG $(\%)=($ Final mean weight, $g$ - Initial mean weight, g)/ Initial mean weight, $\mathrm{g} \times 100 \%$

SGR $\left(\%\right.$ day $\left.^{-1}\right)=[\ln ($ final mean weight $)-\ln$ (initial mean weight)]/ days of culturing $\times 100 \%$

SR $(\%)=$ Final fish number $/$ Initial fish number $\times 100 \%$

DFI $\left(\mathrm{g} \mathrm{fish}^{-1}\right.$ day $\left.^{-1}\right)=$ Total amount of feed given daily, $\mathrm{g} \times$ Number of fish on that particular day.

FCR = Feed intake, g/ (Final mean body weight, g - Initial mean body weight, $g$ )

PER = Fish weight gain (g)/ Amount of protein fed to the fish (g)

The feed cost of the hybrid grouper production in this study was estimated by multiplying the feed cost (Ringgit Malaysia - RM per kg; CCF or LCF) by the FCR from each of the dietary treatments (Bunlipatanon et al., 2014):

Feed cost in hybrid grouper production $(\mathrm{RM} / \mathrm{kg})=$ Feed cost per $\mathrm{kg}(\mathrm{RM} / \mathrm{kg})$ x FCR

\section{Proximate composition analysis}

The CCF, LVF and fish samples were sent to a local accredited laboratory; Chemsain Konsultant Sdn. Bhd, for the proximate composition analyses. The crude protein, fat, moisture and ash contents of the samples were analysed based on the Pearson's Chemical of Food by Egan et al. (1981). Energy and carbohydrate of the samples were analysed based on the Method of Analysis for Nutrition Labeling (Sullivan and Carpenter, 1993). For the CCF and LVF, only single sample from each of them was sent to the laboratory for analysis to get the baseline information on their proximate composition.

In this feeding trial, the five major LVF species used were yellow-striped scad (Selaroides leptolepis), round scad (Decapterus spp.), herrings (Dussumieris spp.), and Indian mackerel (Rastrelliger spp.). For the proximate composition analysis of LVF, equal weight of these species were combined and mixed well as the representative sample.

\section{Organoleptic test}

At the end of the feeding trial, three fish from each cage (totally 6 fish samples from each dietary treatment), weighing $800 \mathrm{~g}-1 \mathrm{~kg}$, were randomly sampled and sacrificed through ice water immersion. The fish were steam-cooked with minimum salt for 40 minutes. The organoleptic test, based on the protocol modified from Fountoulaki et al. (2009), was conducted on 24 non-trained assessors, comprising the hotel guests and management staffs, who were briefed on the procedures earlier before the test. The fish samples were assessed for taste, smell, and texture, in a rating test based on a score scale of 1 to $3(1=$ least preferred; 2 = preferred; 3 = most preferred). The scores of all assessors were calculated to get a mean score of the panel.

\section{Statistical analysis}

As the growth performance data collected was only by duplicate, a least significant difference (LSD) test was conducted (Dodge, 2008) to determine the significance in differences between the data means from the treatments at 0.05 significant different level. A Mann-Whitney U test was conducted to analyse the data collected from the organoleptic test. Significant difference was assumed when $P<0.05$. This statistical test was performed using the SPSS v.17.0 computer programme.

\section{Results}

\section{Proximate composition of the commercially compound feed (CCF) and low-cost feed (LCF).}

Table 1 shows the proximate composition of the CCF and LCF used in this study. The LCF contained higher content of crude protein (85.04\%) compared to the CCF (49.31\%). Nevertheless, the CCF contained higher amounts of crude fat (14.06\%), carbohydrate (28.11\%), minerals $(7.78 \%)$ and energy (1822 kJ) than the LCF $(1.18 \%, 4.72 \%, 2.20 \%$, and $1547 \mathrm{~kJ}$, respectively). 
Table 1. Proximate composition of LCF and CCF based on dry matter basis

\begin{tabular}{lcc}
\hline Parameters & LCF & CCF \\
\hline Crude protein (\%) & 85.04 & 49.31 \\
Crude fat (\%) & 1.18 & 14.06 \\
Carbohydrate (\%) & 4.72 & 28.11 \\
Moisture (\%) & 74.60 & 8.94 \\
Dry matter (\%) & 25.40 & 91.06 \\
Ash (\%) & 2.20 & 7.78 \\
Energy, kcal/100g (kJ) & $370(1547)$ & $436(1822)$ \\
\hline
\end{tabular}

\section{Growth performance, fish whole body proximate composition, and feed cost estimation}

Table 2 shows the growth performance, fish whole body proximate composition, and the estimated feed cost of the hybrid groupers fed CCF and LCF. The fish fed with LCF attained a significantly higher final body weight (971 \pm 24.04 g) than those fed with CCF $(838.517 .68 \mathrm{~g})(\mathrm{P}<0.05)$. Although

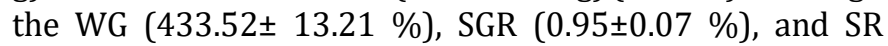
$(93.70 \pm 0.42 \%)$ of fish fed with LCF were higher than those fed with CCF $(360.71 \pm 9.71 \%, 0.90 \%$, and 91.35 $2.76 \%$, respectively), the results were not significantly different ( $P>0.05)$. When the DFI was measured on the wet matter basis, the fish-fed LCF obtained the lower FCR (4.90 \pm 0.28 ) and a significantly higher DFI $\left(22.07 \pm 0.60 \mathrm{~g} \mathrm{day}^{-1}\right)$ than those fed with CCF $\left(1.75 \pm 0.07\right.$ and $6.56 \pm 0.09 \mathrm{~g} \mathrm{day}^{-1}$, respectively). Nevertheless, the DFI (5.61 $\left.\pm 0.15 \mathrm{~g} \mathrm{day}^{-1}\right)$ and FCR (1.24 \pm 0.07) of fish-fed LCF were higher than those fed with CCF (5.97 $\pm 0.08 \mathrm{~g} \mathrm{day}^{-1}$ and $1.59 \pm 0.06$, respectively), although there was no significant difference $(\mathrm{P}>0.05)$.

The price of LCF was RM 1.60 per kg while the retail price of the CCF was RM 5.30 per kg. After multiplying by the respective FCR values, the estimated feed cost of the hybrid grouper fed with LCF and CF were approximately RM 7.84 0.45 and RM 9.28 $\pm 0.37 / \mathrm{kg}$ of fish, respectively $(\mathrm{P}>0.05)$. On the other hand, the whole body crude protein (19.80$19.75 \%)$, crude fat $(0.75-0.90 \%)$, moisture (76.80 $75.60 \%)$, and ash (1.65 - 2.00\%) contents of the fish fed with LCF or CCF were not significantly different $(\mathrm{P}>0.05)$.

\section{Organoleptic test}

Figure 1 shows the scores given to the smell, texture, and taste of the steam-cooked hybrid grouper fed with LCF and CCF. An interesting score value of approximately 2 for all categories was found, and there was no significant difference between the fish fed with LCF nor CCF.
Table 2. Growth performances, feed efficiencies and feed cost of Sabah groupers fed with LCF and CCF. All results are shown in mean \pm S.D, and the different superscripts indicates the significant difference at 0.05 level between the values within the same row.

\begin{tabular}{|c|c|c|}
\hline $\begin{array}{l}\text { Growth } \\
\text { performance } \\
\text { indices }\end{array}$ & LCF & CCF \\
\hline Final body weight (g) & $971.00 \pm 24.04^{\mathrm{a}}$ & $838.50 \pm 17.68^{b}$ \\
\hline Weight gain (\%) & $433.52 \pm 13.21^{\mathrm{a}}$ & $360.71 \pm 9.71^{\mathrm{a}}$ \\
\hline $\begin{array}{l}\text { Specific growth rate } \\
\left(\% \text { day }^{-1}\right)\end{array}$ & $0.95 \pm 0.07^{a}$ & $0.90 \pm 0.00^{\mathrm{a}}$ \\
\hline Survival ratio (\%) & $93.70 \pm 0.42^{\mathrm{a}}$ & $91.35 \pm 2.76^{\mathrm{a}}$ \\
\hline \multicolumn{3}{|l|}{ Daily feed intake } \\
\hline - WM (g day $\left.{ }^{-1}\right)$ & $22.07 \pm 0.60^{\mathrm{a}}$ & $6.56 \pm 0.09 \mathrm{~b}$ \\
\hline - DM (g day $\left.{ }^{-1}\right)$ & $5.61 \pm 0.15$ & $5.97 \pm 0.08$ \\
\hline \multicolumn{3}{|l|}{ Feed conversion ratio } \\
\hline$-\mathrm{WM}$ & $4.90 \pm 0.28^{a}$ & $1.75 \pm 0.07^{a}$ \\
\hline$-\mathrm{DM}$ & $1.24 \pm 0.07$ & $1.59 \pm 0.06$ \\
\hline $\begin{array}{l}\text { Protein efficiency } \\
\text { ratio }\end{array}$ & $0.95 \pm 0.05^{\mathrm{a}}$ & $1.27 \pm 0.05^{\mathrm{a}}$ \\
\hline
\end{tabular}

\section{Feed cost}

estimation

\begin{tabular}{lcc}
\hline $\begin{array}{l}\text { Average Feed Price } \\
\text { (RM/kg) }\end{array}$ & $1.60 \pm 0.00^{\mathrm{a}}$ & $5.30 \pm 0.00^{\mathrm{a}}$ \\
$\begin{array}{l}\text { Feed cost }(\mathrm{RM} / \mathrm{kg} \\
\text { fish) }\end{array}$ & $7.84 \pm 0.45^{\mathrm{a}}$ & $9.28 \pm 0.37^{\mathrm{a}}$
\end{tabular}

fish)

$7.84 \pm 0.45^{a}-9.28 \pm 0.37$

\section{Fish whole body proximate composition}

\begin{tabular}{lcc}
\hline Protein (\%) & $19.80 \pm 0.42^{\mathrm{a}}$ & $19.75 \pm 0.21^{\mathrm{a}}$ \\
Fat $(\%)$ & $0.75 \pm 0.21^{\mathrm{a}}$ & $0.90 \pm 0.00^{\mathrm{a}}$ \\
Moisture (\%) & $76.80 \pm 0.28^{\mathrm{a}}$ & $75.60 \pm 1.13^{\mathrm{a}}$ \\
Ash $(\%)$ & $1.65 \pm 0.07^{\mathrm{a}}$ & $2.00 \pm 0.00^{\mathrm{a}}$ \\
\hline
\end{tabular}

WM - Wet matter basis, DM - Dry matter basis

\section{Discussion}

In this study, the hybrid groupers fed with LCF attained better growth performance than those fed with CCF. This finding is consistent with the general claims by the local farmers. Although on the wet weight basis, the DFI of fish fed with LCF was significantly higher and the FCR was lower, the opposite results were found when the DFI was converted to the dry matter basis. Fish fed with LCF attained a slightly lower DFI but better FCR than those fed with CCF. These findings are in agreement with those of Bunlipatanon et al. (2014) that emphasized that the higher moisture content in LCF should not be neglected, when the feed intake of LCF and CCF are recorded for a fair comparison in a scientific study. In fact, similar results were also reported on cage farming of 
other marine finfish, including the Asian seabass (Lates calcarifer), tiger grouper (E. fuscoguttatus), humpback grouper (Cromileptes altivelis), coral trout (Plectropomus leopardus) and sand grouper (E. corallicola). These fish have yielded the higher weight gain when ed with LCF, compared to CCF (Tacon et al., 1991a, b; Bunlipatanon et al., 2014; Rimmer et al, 2016). However, there were contradictory results reported in some previous studies. Ching et al. (2019) conducted an eight-week feeding trial on the hybrid grouper in the sea cages at Kota Belud, and found that the fish fed with CCF attained significantly higher weight gain than those fed with the LCF. Such differences may be due to the LCF species used. Commonly, the LCF species used for feeding in cage culture in Sabah is the locally available sardine, Sardinella spp. (Shapawi et al., 2011). The major LCF species used in the feeding trial by Ching et al. (2019) was also Sardinella spp. In this study, multiple species of LCF (S. leptolepis, Decapterus spp., Dussumieris spp. and Rastrelliger spp.) were used for the feeding. Although the crude protein level of the LCF mixture in this study (85.04\% in dry matter form) was higher than that of the common Sardinella spp. (approximately 70\% in dry matter form as reported by Shapawi et al., 2011), the possible effects of feeding single or multiple LCF species on the growth performance of the farmed fish is currently unknown. Further study is necessary to provide a scientific basis for interpretation.

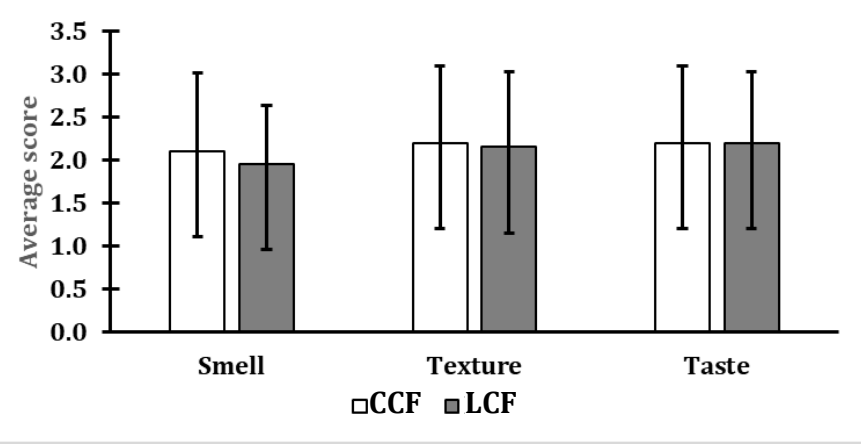

Figure 1. The scoring for the organoleptic test. Vertical bars show the standard deviation of the data. $\mathrm{CCF}$ - commercially compounded feed; LCF - low-cost fish.

In addition to better fish growth performance, this study also found that the estimated feed cost of the hybrid grouper production fed with LCF was lower than those fed CCF, although the prices were not significantly different. This finding again, was concordant with the claims made by the local farmers as mentioned earlier. These could be largely due to the higher prices of CCF in Sabah. In fact, Sabah's aquaculture industry has to rely on CCF produced in West Malaysia and those from overseas, as there is no local commercial fish feed mill in Sabah, causing the high price and limited choice of CCF. Most farmers in Sabah still prefer to use LCF due to easier access, quantity and a lower price when purchased at the landing jetties, compared to CCF. Indeed, the wholesale price of LCF can be cheaper than CCF, according to the statistics from the Department of Fisheries Sabah - DoFS (2018).

Despite the poorer growth performance and higher production cost of the hybrid grouper fed using CCF, their organoleptic qualities including smell, texture, and taste were comparable to those fed with LCF (Figure 1). This outcome is similar to the observations reported by Ching et al. (2019) on the hybrid grouper; suggesting that feeding LCF or CCF may not affect the local consumer preference. As fish consumption preference amongst consumers varies (according to background, region, culture, habit, etc.) (Can et al., 2015), this study does not intend to compare the findings with those from other previous studies.

Although feeding with LCF holds more advantage over CCF as determined in this study, it should be noted that the price, supply and quality of LCF are highly volatile. Hence, feeding with LCF may not be cost-efficient all year round. According to the statistics from DoFM (2018) and observation by authors at local fish landing jetties, the wholesale price of LCF ranged from RM0.7/kg to beyond $\mathrm{RM} 2$, depending on the quality and supply at a given time. Besides that, feeding with LCF is an unsustainable practice that excessively exploits the marine ecosystem. This can be imagined from the fact that in 2018, the trawler industry alone has contributed $96 \%$ of total LCF landings in Sabah (DoFS, 2018). Demersal species fisheries stock assessment in the coastal area conducted by Fisheries Research Institute (FRI) of DOFM in between 1960-2016 shows that the stock has drastically declined to $15 \%$ from the 1960 baseline $(150,710 \mathrm{mt}$ to $23,236 \mathrm{mt})$ and this was mainly attributed to the trawling activities (Fisheries Research Institute - FRI, 2017). In order to protect the Sabah fisheries resources, Sabah Agricultural and Food Industries Ministry is working on strengthening the fisheries management, including banning trawlers in future (Chan, 2019). Given that the marine finfish farming in Sabah relies highly on LCF, the idea to ban trawling is likely to impact the industry.

Over the past decades, significant efforts have been made to reduce the inclusion level of fishmeal and fish oil in aquafeed production (Hasan, 2017). Feeding with CCF formulated with alternative sources of protein in the aquaculture will contribute significantly to sustainable aquaculture (Turchini and Trushenski, 2018; Hua et al., 2019). In order to convince the farmers in Sabah to adopt CCF, future research should focus on species-specific diet formulation comprising ingredients from sustainable sources to make aquaculture more profitable to farmers and consumers, and reduce its ecological footprint. 


\section{Conclusion}

This study assessed the efficacy of using LCF and CCF aquaculture production of the hybrid grouper in an experimental trial lasting over a period of 25-weeks. The data suggested that it was more efficient to feed the hybrid groupers with LCF compared to CCF in terms of growth performance and feed conversion ratio. Feeding LCF was also more economical. However, long-term dependence on LCF is an unsustainable practice as it exerts a strong impact on the marine environment by causing increase in fishing pressure and destructive fishing. Further research should be directed towards improving the diet formulation with alternative sources of protein, growth performance optimisation and cost- reduction in order to motivate the farmers to adopt CCF. It was also found that the organoleptic quality of the fish was not affected by the feed types used.

\section{Acknowledgment}

This trial was funded by WWF-Malaysia's General Funds (MA020113000GENF). The authors would like to express gratitude to the management and guests of Shangri-La's Tanjung Aru Resort and Spa for hosting and participating in the organoleptic test. We also thank Prof. Dr. Gunzo Kawamura for his valuable comments, particularly on statistical analysis.

\section{References}

Bunlipatanon, P., Songseechan, N., Kongkeo, H., Abery, N.W. \& De Silva. S.S. (2014). Comparative efficacy of trash fish versus compounded commercial feeds in cage aquaculture of Asian Seabass (Lates calcarifer) (Bloch) and tiger grouper (Epinephelus fuscoguttatus) (Forsskål). Aquaculture Research 45(3), 373-388.

Can, M. F., Günlü, A. \& Can, H.Y. (2015). Fish consumption preferences and factors influencing it. Food Science and Technology 35(2), 339-246.

Chan, J. (2019). Sabah government to ban fishing trawlers in bid to protect environment. Malaymail. https://www.malaymail.com/news/ malaysia/2019/09/03/sabah-govt-to-ban-fishing-trawlers-in-bid-toprotect-environment/1786848

Ching, F.F., Mohamad, N.Z.S., Shapawi, R., Shaleh, S.R.M., Othman, R., Ajuh, M. \& Senoo, S. (2019). Comparison on growth performance and organoleptic quality of hybrid grouper fed with prey fish and formulated feed. In: Abstract Book of International Conference on Marine Science and Aquaculture 2019 - Marine Biodiversity for Sustainable Management of Aquaculture and Ecosystem Services, Kota Kinabalu, pp 63. Universiti Malaysia Sabah, Sabah, Malaysia.

Ch'ng, C.L. \& Senoo, S. (2008). Egg and larval development of a new hybrid grouper, tiger grouper Epinephelus fuscoguttatus x giant grouper $E$. lanceolatus. Aquaculture Science 56, 505-512.

Department of Fisheries Sabah - DoFS. (2018). Annual fisheries statistics for 2018. Kota Kinabalu. Department of Fisheries Sabah - DoFS.

Department of Fisheries Malaysia - DoFM. (2018). Annual fisheries $\begin{array}{llll}\text { statistics } & \text { for } & \text { Kuala } & \\ \end{array}$ https://www.dof.gov.my/index.php/pages/view/3343 (Downloaded at 14 August 2019).

Dodge, Y. (2008). The Concise Encyclopedia of Statistics. Springer, 432pp. New York.
Egan, H., Kirk, R.S., Sawyer, R. \& Pearson, D. (1981). Pearson's Chemical Analysis of Foods. 8th ed. Churchill Livingstone, 591 pp. Edinburgh, New York.

Fisheries Research Institute - FRI (2017). Fisheries Resources Survey in Malaysia Waters 2013-2016: executive summary. Department of Fisheries Malaysia - DoFM. Ministry of Agriculture and Agro-based Industry Malaysia.

Fountoulaki, E., Vasilaki, A., Hurtado, R., Grigorakis, K., Karacostas, I., Nengas, I., Rigos, G., Kotzamanis, Y., Venou, B. \& Alexis, M.N. (2009). Fish oil substitution by vegetable oils in commercial diets for gilthead sea bream (Sparus aurata L.); effects on growth performance, flesh quality and fillet fatty acid profile: Recovery of fatty acid profiles by a fish oil finishing diet under fluctuating water temperatures. Aquaculture 289, 317-326.

Gomez, D.K., Mori, K., Okiyana, Y., Nakai, T, Park, S. C. (2010). Trash fish can be a source of betanodavirus for cultured marine fish. Aquaculture 302 158-163.

Hasan, M.R. (2017). Feeding Global Aquaculture Growth. Rome. Food and Agriculture Organization of United Nations- FAO.

Hua, K., Cobcroft, J.M., Cole, A., Condon, K., Jerry, D.R., Mangott., A., Praeger, C., Vucko, M.J., Zeng, C., Zenger, K., and Strugnell, J.M. (2019). The future of aquatic protein: implications for protein sources in aquaculture diets. One Earth 1(3), 316-329.

Kim, D.H. (2015). Low-value fish used as feed is a source of disease in farmed fish. Fisheries and Aquatic Sciences 18, 203-209.

Lajimin, S., Abd Razak, A., Denil, D.J., Ransangan, J., Abdul Wahid, M.E., Sade, A. (2015). First detection of Megalocytivirus (Iridoviridae) in trash fish used for aquaculture feed in Sabah, Malaysia. International Journal of Aquatic Science 6, 54-66.

Ng, X.K. (2017). Consultancy for case study of aquaculture in Peninsular Malaysia: Comparison between Aquaculture Improvement Project Farms and Non-Aquaculture Improvement Project farms. WWF Technical Report. World Wildlife Fund Malaysia, Selangor, Malaysia.

Rachmansyah, Usman, Palinggi, N.N. \& Williams, K. (2009). Formulated feed for tiger grouper grow-out. In: Aquaculture Asia Magazine Vol. XIV No. 2 April-June 2009 (S. Wilkinson, ed.), pp 30-36. Network of Aquaculture Centres in Asia-Pacific (NACA), Bangkok, Thailand.

Rimmer, M.A., Sudja, W., Indradjaja, D.D., Giri, N.A. \& Laining, A. (2016). Compound feed for grouper aquaculture-why has adoption been poor? AQUA Culture Asia Pacific Magazine 12, 25-28.

Sim, S.Y., Rimmer, M.A., Williams, K., Toledo, J.D., Sugama, K., Rumengan, I. \& Philips, M.J. (2005). A Practical Guide to Feeds and Feed Management for Cultured Groupers. NACA, 25 pp. Bangkok, Thailand.

Shapawi, R., Mustafa, S. \& Ng, W.K. (2011). A comparison of the growth performance and body composition of the humpback grouper, Cromileptes altivelis fed on farm-made feeds, commercial feeds or trash fish. Journal of Fisheries and Aquatic Science 6, 523-534.

Shapawi, R. Ching, F.A., Senoo, S. \& Mustafa, S. (2018). Nutrition, growth and resilience of tiger grouper (Epinephelus fuscoguttatus) x giant grouper (Epinephelus lanceolatus) hybrid-a review. Reviews in Aquaculture.

Sullivan, D.M. \& Carpenter, D.E. (1993). Methods of Analysis for Nutrition Labeling. AOAC International, 624pp. Arlington VA.

Tacon, A.G.J., Rausin, N., Kadari, M. \& Cornelis, P. (1991a). The food and feeding of marine in floating cages at the National Sea-farming Development Centre, Lampung, Indonesia: rabbitfish, Siganus canaliculatus (Park). Aquaculture and Fisheries Management 21, 375-390.

Tacon, A.G.J., Rausin, N., Kadari, M. \& Cornelis, P. (1991b). The food and feeding of tropical marine fishes in floating net cages: Asian seabass, Lates calcarifer (Bloch), and brown spotted grouper, Epinephelus tauvina (Forskal). Aquaculture and Fisheries Management 22, 165-182.

Turchini, G.M. and Trushenski, J.T. (2018). Thoughts for the future of aquaculture nutrition: realigning perspectives to reflect contemporary issues related to judicious use of marine resources in aquafeeds. American Fisheries Society 81(1) , 13-39 